\title{
ANTI-GOVERNMENT NETWORKS IN CIVIL CONFLICTS: HOW NETWORK STRUCTURES AFFECT CONFLICTUAL BEHAVIOR
}

\author{
NILS W. METTERNICH, CASSY DORFF, MAX GALLOP, SIMON WESCHLE,
} AND MICHAEL D. WARD

\begin{abstract}
In this article, we combine a game-theoretic treatment of public goods provision in networks with a statistical network analysis to show that fragmented opposition network structures lead to an increase in conflictual actions. Current literature concentrates on the dyadic relationship between the government and potential challengers. We shift the focus toward exploring how network structures affect the strategic behavior of political actors. We derive and examine testable hypotheses and use latent space analysis to infer actors' positions vis-à-vis each other in the network. Network structure is examined and used to test our hypotheses with data on conflicts in Thailand 2001-2010. We show the influential rôle of network structure in generating conflictual behavior.
\end{abstract}

The 2011 uprisings in Egypt, Tunisia, and Syria demonstrate that government challengers rarely come alone. They interact, cooperate, and compete with other domestic opponents of the government, forming anti-government networks. Civil conflicts frequently involve multiple groups challenging the government at the same time. Despite this, most scholars have conceptualized civil conflicts as dyadic events between the government and a single opposition group. Challenging this perspective, recent research highlights rebel alliances and strategic interactions among anti-government groups as important aspects of civil conflict dynamics (Cunningham

Date: March 7, 2013, Final Version.

This project was undertaken in the framework of an initiative funded by the Information Processing Technology Office of the Defense Advanced Research Projects Agency aimed at producing models to provide an Integrated Crisis Early Warning Systems (ICEWS) for decision makers in the U.S. defense community. The holding grant is to the Lockheed Martin Corporation, Contract FA8650-07-C-7749. For helpful insights we thank Scott de Marchi, Florian Hollenbach, Jan Pierskalla, and Anna Schultz. All the bad ideas and mistakes are our own. An earlier version was presented at the conference "Theory and Methods in the Study of Civil War", Centre for the Study of Civil War, PRIO, Oslo 9-10 June 2011. All data and replication files can be found at http://dvn.iq.harvard.edu/dvn/dv/mward as well as at the dataverse for the Journal: http:

//dvn.iq.harvard.edu/dvn/dv/ajps.

Corresponding author: Michael D. Ward). 
et al., 2009; Fjelde and Nilsson, 2009). We extend these insights by conceptualizing opposition groups as part of a larger anti-government network, emphasizing the interactive nature of civil conflicts. The idea of an anti-government network not only has intuitive appeal, but also provides a conceptual framework to analyze how dynamics within the network affect the behavior of its members towards the government and vice-versa. The network perspective stresses that the behavior of opposition groups is interdependent and that dynamics within the anti-government network are likely to affect actions vis-à-vis the government. To our knowledge, this study is unique in applying a theoretically and empirically integrated network analysis approach to the study of civil conflict.

In recent years, network analysis has been increasingly influential in political science. The appeal of network analysis can be attributed to the fact that it offers a systematic way to analyze a fundamental assumption of the social sciences: the interdependence of behavior among social actors. While the idea of networks is prominent in many theoretical considerations and descriptive analyses, far less research has focused on inferential, as opposed to descriptive, analysis of networks. ${ }^{1}$ In this article, we infer the network structure in which anti-government actors interact. In this way, we take into account the interdependence of anti-government actors and simultaneously analyze its consequences for domestic conflict.

Focusing on anti-government networks allows us to move beyond structural factors, such as economic development or political institutions, which are often found to be the most robust explanatory factors in models of civil conflicts (e.g., Fearon and Laitin, 2003, Collier and Hoeffler, 2004; Hegre et al., 2001; Hegre and Sambanis, 2006). The strong relationship between economic development and armed conflict obscures the fact that structural factors fare much better at predicting peace than conflict. Furthermore, and not surprisingly, structural factors have difficulties explaining the onset of conflict and accounting for its dynamics. Our study

\footnotetext{
${ }^{1}$ One important exception in the realm of collective action is the work of Siegel (2009, 2011), which focuses on collective action problems within networks.
} 
investigates whether the consideration of social interactions between anti-government groups can improve our understanding and ultimately lead to better predictions of conflict escalation, exactly where structural factors would suggest peace. To empirically test our theoretical considerations, we focus on the case of Thailand. We analyze Thailand because in earlier phases of our own research, structural models under-predicted conflict escalation in this country. In addition, Thailand has two ongoing internal conflicts, complicating aggregated, country-level analysis. This challenges the explanation of conflict evolution in Thailand, since it is not only multidimensional, and spatially disjoint, but it also encompasses pro- and anti-government groups with changing memberships. We argue that an aggregated, structural economic explanation has insufficient purchase in explaining conflict dynamics in Thailand.

The limitations of structural economic explanations become clearer when examining the relationship between conflict occurrence and economic development in Thailand. Despite relatively high levels of economic development, Thailand has repeatedly been involved in violent struggles. Between 1991 and 2004, peaceful countries had a median GDP per capita of roughly $\$ 5700$. In contrast, countries experiencing civil conflict had a median GDP per capita less than $\$ 2600$. Strikingly, Thailand had a GDP per capita of $\$ 7700$ at the beginning of its recent conflict and is the second most developed country that witnessed a civil conflict onset in this time period. Only Russia ranks higher in experiencing conflict onsets, due to the events in the regions of Chechnya and Dagestan. Figure 1 illustrates this insight by sorting and plotting country years of conflict in relation to per capita GDP, using data from Gleditsch (2002).

Figure 1 about here.

In light of this empirical puzzle, we ask whether examining social networks and the interaction among government challengers can improve our understanding and facilitate better predictions of conflict processes. We argue that the structure of social networks is an important aspect of internal conflicts because it shapes the incentives of government opponents to either contribute to anti-government actions or free-ride on the efforts of others. This issue is especially salient in internal conflicts since anti-government groups face a fundamental collective action problem: 
how can the groups challenge the government without free-riders jeopardizing the efficiency of the overall movement (Lichbach, 1995)? Since the toppling of the government or even the security of the anti-government network can be seen as a public good with non-rival and non-excludable benefits to any anti-government actor (Tullock, 1971), major insights about collective action in the international context (Olson and Zeckhauser, 1966; Sandler and Hartley, 2001) should also hold for domestic contexts.

We argue that network structures condition the extent to which members in the antigovernment network can benefit from the efforts of others. The reasoning is straightforward: anti-government actors are more likely to benefit from anti-government efforts by other actors that share preferences and goals than from efforts by those positioned further away in terms of the relevant social context. For example, if a group prevails over the government, its allies are more likely than its competitors to gain influential positions in the post-conflict government or see more favorable policies enacted. Accordingly, there are more incentives to free-ride on actors that are closer in social space. However, the more anti-government actors free-ride, the more difficult it is for the anti-government network as whole to engage in conflictual behavior with the government. Hence, we expect that network structures are important in explaining conflict dynamics between the government and its opposition.

We proceed by describing the political context of conflict in Thailand, presenting our theoretical argument, and deriving its empirical implications. Next, we provide a discussion of the latent-space approach to derive the structure of the anti-government network in Thailand as it has evolved. Our findings support our theoretical argument that high levels of conflictual events are more likely when the network structure allows for high aggregate levels of public good provision. To conclude we point out limitations of this study and discuss further research on social networks and civil conflict.

Thailand. There are two ongoing internal political conflicts in Thailand. The first is largely related to one leader whose time in office spurred a deep divide in public opinion in Thailand. 
Following the implementation of a new democratic constitution in 1997 and the resulting elections in 2001, Thaksin Shinawatra, the founder of the Thai Rak Thai party and an influential business leader, was elected prime minister. Thaksin entered office facing widespread economic problems resulting from the 1997 Asian economic crisis (for a timeline of these events see Figure 2). Thaksin and his party enacted healthcare reforms and established aid to farmers and rural communities as a central tenet of policy. Essential to the success of these reforms were institutional modifications that reduced the number of political parties and thus increased the power of Thaksin compared to coalition partners and intra-party factions (Hicken, 2006). Also during his tenure, Thaksin introduced a harsh and controversial crackdown on drug trafficking organizations in an effort to stem conflictual events frequently occurring at the Thailand-Burma border.

In 2006 following the year of his re-election, Thaksin faced growing opposition throughout Thailand resulting in numerous protests often organized by the People's Alliance for Democracy (PAD). Eventually, Thaksin and his party were ousted from office by a non-violent military coup (see the upper rug of Figure 2 for regime transitions). In 2007 the military leadership passed a new constitution that was used to pursue the charges against Thaksin. In the early months of 2008, Thaksin sought exile and did not return to Thailand to hear the Supreme Court's sentence against him. Later that year, Thaksin was accused of corruption and election fraud, which he denied. In 2009 Thaksin was formally found guilty of corruption and sentenced to two years in prison. Thaksin and his political party, the Thai Rak Thai, were banned from participation in the national political process. The debate over whether these corruption charges were legitimate is active and ongoing, especially after his sister was elected Thailand's first female prime minister in 2011.

Figure 2 about here.

The transitional military government organized elections in 2007. The People's Power Party (PPP) became the leader of the coalition government following the election. However, leading 
party officials were accused of election fraud and the party was dissolved by the Supreme Court. ${ }^{2}$ After this, the opposing Democratic Party formed a coalition government in 2008. At this time demonstrations, riots, and protests characterized the political landscape of Thailand. The bottom rug in Figure 2 illustrates the rise of conflictual events. Much of the turmoil was born out of a conflict between Thaksin supporters (known as Red Shirts) and anti-Thaksin groups (or Yellow Shirts). The Red Shirts, who function largely as a political umbrella organization composed of former members of the People's Power Party and other anti-PAD movements, have routinely initiated strikes and protests in Northern Thailand and Bangkok. The year 2008 represents a tumultuous period of leadership transition in Thailand as three different prime ministers rotated through office. In late 2008, the Constitutional Court removed Prime Minister Somchai Wongsawat from office, disbanding the People's Power Party and banning its leaders from the political process for five years. Abhistit Vejjajive, the young leader of the Democrat Party, was supported by a coalition within parliament and secured his place as prime minister. Despite domestic turmoil and significant anti-government protests, Abhistit Vejjajive remained prime minister until power shifted in 2011 to Yingluck Shinawatra, following the general elections where the Pheu Thai Party (the third iteration of the Thai Rak Thai organization) won 265 of 500 seats in the House of Representatives. Yingluck Shinawatra's rise to power is quite controversial, given her background as a powerful business woman who frequently worked alongside her brother, Thaksin Shinawatra.

A second political conflict emanates from the Muslim region of Patani, which borders Malaysia. The political objectives of the numerous anti-government groups in the region range from complete independence to achieving higher levels of autonomy from the central government. The Uppsala Conflict Data Project (Gleditsch et al., 2002) reports that as the government limited the once coordinating rôle of the Patani United Liberation Organization, a number of rival

\footnotetext{
2The People's Power Party emerged from from the remnants of Thaksin's Thai Rak Thai party that was dissolved following the 2006 coup.
} 
organizations became active in the armed conflict. Separatist conflict plagued this area of Thailand for years, but violence escalated in 2004, prompting then Prime Minister Thaksin to impose martial law and deploy troops in the area in an effort to quell the conflict. According to the best estimates available, the conflict between separatist groups and the government in the Patani region led to approximately 940 battle related deaths between 2003 and 2008 (UCDP, 2011). In addition both the separatist conflict and the conflict over government power has taken the lives of about 1400 civilians during this time (Eck and Hultman, 2007). The government's attempt to halt the conflict was not entirely successful, and over the last several years violence has continued to grow in scope and intensity. Figure 2 shows the number of conflictual events between the government and members of the anti-government network generally increasing until 2007 and declining thereafter.

\section{THEORY}

As we have outlined, anti-government groups have to deal with a significant collective action problem: how can groups challenge the government without free-riders jeopardizing the efficacy of the overall movement (Lichbach, 1995)? In the context of intra-state conflicts, the collective action problem has mainly been studied at the micro and individual recruitment level. We shift the focus to anti-government groups and the conditions under which these groups are able to effectively challenge the government and maintain their movement. An important aspect of our theoretical approach is that we conceptualize anti-government groups as being part of a larger anti-government network. However, the ultimate goals of the network members, for example to topple the government or provide security for its members, can be seen as public goods with non-rival and non-excludable benefits to connected actors within the anti-government network. We outline the conditions under which this gives rise to higher levels of conflictual events. We demonstrate that corner equilibria of public good provision within the anti-government network lead to higher aggregate levels of the public good. 
Main Argument. Anti-government actors, such as rebel organizations, actively protesting political parties, or demonstrating social movements, are not independent of each other. For example, efforts of one actor to challenge the government should decrease the state's ability to fight other anti-government groups. More importantly, this interdependence among antigovernment groups is likely to be strategic since we expect actors to condition their efforts on the behavior of others. While we do not contest previous ideas that actor characteristics or the number of government challengers matter (Cunningham, 2006), we argue the that this strategic connectivity in the social space motivates a network perspective to analyze the behavior of antigovernment actors. We focus on how the structure of the network of anti-government actors affects the conflict intensity between anti-government groups and the government.

One of the crucial challenges anti-government actors face is the problem of collective action. We explore the network conditions under which the under-provision of public goods becomes more likely, and illustrate how this impacts conflict escalation. Free-riding arises in civil conflicts because anti-government actors cannot be excluded from the benefits of secession, removing the existing government, or improved security for opposition members. However, an actor's position in the network can restrict the degree to which it benefits from the provision of a public good. Imagine two anti-government actors that are closely related in social space by similar preferences, a common ethnicity, or a history of cooperation. It is likely that if one of the two actors deposes the government and takes office, it will implement institutions and policies that overlap with the preferences of the other actor. In this situation there are incentives to free-ride, because an actor's preferred post-conflict institutions and policies will be implemented largely or entirely independently of their own efforts to create such an outcome. Similarly, if two anti-government groups are close in social space this implies that their recruitment and support base are similar, and any public good provided by one group is likely to benefit the other as well.

But not all anti-government actors are close in social space. In this case there are fewer incentives to free-ride, because even if the other actor can depose the current government on its 
own and take over, it is likely to implement policies and institutions that are not as close to the interest of the second challenger. Hence, the benefits from free-riding are restricted to actors that are close in the social space. If actors are far apart, it is unlikely that their production of a public good has any effect on each other. They thus have incentives to secure their political share in the post-conflict situation by fighting the government on their own. This logic implies that actors' relative position vis-à-vis each other in the social space conditions the transfer of public goods and hence enhances or depresses incentives to free-ride on the anti-government efforts of others. This is an important insight and we argue that it has a substantial and immediate effect on escalation patterns. ${ }^{3}$

Public Goods Provision in Strategic Networks. For a more rigorous analysis of this insight, we leverage the strategic networks literature. The main question in this game theoretical literature is how network structures affect equilibrium outcomes. While earlier work in this field has resulted in more general insights about network structures and equilibrium outcomes (Bramoullé and Kranton, 2007, Galeotti et al., 2010), recent work has derived more precise conditions under which certain network characteristics result in specific sets of equilibria (Bramoullé et al., 2011). These results apply to simultaneous N-player games that can be expressed as a potential function. An important insight of this research is that the lowest eigenvalue of a given network captures the relevant shape of a game's potential function, informing us about its concavity and thus equilibrium outcomes. The following section outlines the major insights of Bramoullé et al. (2011) and identifies the empirical implications for our study.

\footnotetext{
${ }^{3}$ Here we depart significantly from the insights about the relationship between anti-government networks and rebellion in Staniland (2012). There the argument is that cohesive networks are better able to employ natural resources and foreign funding leading to higher levels of violence against the government, while networks with cleavages will be less able to use these resources to attack the government. We believe this claim ignores the impact of network structure on solving collective action problems to attack the government.
} 
Our theoretical approach is interested in the provision of security with non-rival and nonexcludable benefits to connected actors, where the specific network structure defines the connectivity. In a first step, we focus on an anti-government network with $n$ actors that want to depose the current government or force it to make major political concessions. It is represented by $\mathbf{A}$, an $n \times n$ connectivity matrix. Let us assume that any effort $e_{i} \in[0,+\infty)$ by any network member $i$ contributing to the anti-government cause has a non-rival and non-excludable benefit to all actors connected to $i$, thereby taking the characteristics of a localized public good. Let $\mathbf{e}=\left(e_{1}, \ldots, e_{n}\right)$ denote a vector of all network members' anti-government efforts.

We make the crucial assumption that the connectivity matrix of the anti-government network A informs us about whether member $i$ can benefit from $j$ 's anti-government efforts. This means that we put some restriction on who benefits from the anti-government efforts of others. More formally, if $a_{i j}=1$, actor $j$ will benefit from effort $e_{i}$ directly, while this is not the case if $a_{i j}=0$. In the following, without loss of generality we assume symmetry: $a_{i j}=a_{j i}$. In line with Bramoullé et al. (2011), two actors are connected, linked, related, or neighbors whenever $a_{i j}=a_{j i}=1$. These connectivity assumptions mean that the utility function of each actor $i$ depends on her own effort $e_{i}$ and the effort levels of the other actors $e_{\neq i}$. The impact of the others' actions depends on who they are connected to as expressed in the connectivity matrix A and the impact factor $\delta \in[0,1]$. A higher $\delta$ means that $i$ profits more from the efforts of others.

Consider a simple game of public good provision in networks that can be applied to our idea of anti-government alliances. This game is studied by Bramoullé and Kranton (2007). Each actor's utility function takes the following form:

$$
U_{i}\left(e_{i}, e_{\neq i}, \delta, \mathbf{A}\right)=b\left(e_{i}+\delta \sum_{j} a_{i j} e_{j}\right)-k e_{i}
$$

where $b(\cdot) \in \mathbb{R}_{+}$is strictly increasing and strictly concave and $k_{i}>0$ is the constant marginal cost of $e_{i}$, such that $b^{\prime}(0)>k>b^{\prime}(+\infty)$. It is straightforward that if $i$ acts in isolation, $\delta=0$ and/or any $a_{i j}=0$, the maximizing problem collapses to $U_{i}\left(e_{i}, e_{\neq i}, \delta, \mathbf{A}\right)=b\left(e_{i}\right)-k e_{i}$. This 
means $i$ 's optimal level of effort in isolation, $\bar{e}_{i}$, is where the marginal efforts are equal to the marginal costs.

For every actor $i$ the best response function in this game is:

$$
\begin{array}{ll}
e_{i}^{*}=\bar{e}_{i}-\delta \sum_{j} a_{i j} e_{j} & \text { if } \delta \sum_{j} a_{i j} e_{j}<\bar{e}_{i} \\
e_{i}^{*}=0 & \text { if } \delta \sum_{j} a_{i j} e_{j} \geq \bar{e}_{i}
\end{array}
$$

The reasoning behind $i$ 's best response is that if the weighted sum of the other network members $\delta \sum_{j} a_{i j} e_{j}$ are less than what $i$ would have allocated in isolation, $i$ invests the difference. Similarly, if $\delta \sum_{j} a_{i j} e_{j}$ surmounts $\bar{e}_{i}, i$ free-rides on the network members' efforts. Normalizing $\bar{e}_{i}=1$ for all $i$ allows us to express the best reply function as $f_{i}(e, \delta, \mathbf{A})=\max \left(0,1-\delta \sum_{j} a_{i j} e_{j}\right)$. A Nash equilibrium of this game is a vector $\mathbf{e}^{*}$ of length $n$ with elements $e_{i}^{*} \in[0,1]$ that simultaneously satisfies $x_{i}=f_{i}(x, \delta, \mathbf{A})$ for all members of the network.

Bramoullé et al. (2011) demonstrate that any game with this structure can be expressed as a potential function $\varphi(e, \delta, \mathbf{A})$ to find the set of Nash equilibria for a given $\mathbf{A}$ and $\delta$. A potential function exists if the incentives of all actors to change their strategies can be expressed in one global function $\varphi$ (Monderer and Shapley, 1996). Bramoullé et al. (2011) show that the set of Nash equilibria is equal to the local and global maxima and saddle points of the potential function $\varphi(e, \delta, \mathbf{A})$. Crucially, they find that the lowest eigenvalue of a network, $\lambda_{\min }(\mathbf{A})$, captures the relevant shape of the potential function. The potential function is strictly concave if and only if $\delta<\frac{-1}{\lambda_{\min }(\mathbf{A})}$. It follows that if $\varphi(e, \delta, \mathbf{A})$ is strictly concave, there exists a stable Nash equilibrium that can be an interior or a corner solution. Moreover, Bramoullé et al. (2011) propose that $\delta<\frac{-1}{\lambda_{\min }(\mathbf{A})}$ is also a necessary and sufficient condition for uniqueness since this condition guarantees that the Nash equilibrium vector $\mathbf{e}^{*}$ is a locally strict maximum, implying that the system converges back to the same maxima if small strategy divergences occur.

Lowest Eigenvalues and the Shape of the Network. The main insight of Bramoullé et al. (2011) is that small, lowest eigenvalues (e.g. -8) of a network are associated with corner 
solutions, while eigenvalues closer to -1 typically foster unique interior solutions, but may also be unique corner solutions. For our purposes it is important to have a firm understanding about the relationship between the lowest eigenvalue and the actual shape of the network. ${ }^{4}$

Studies on the lowest eigenvalue of a network show that bipartite networks have the smallest lowest eigenvalues of any adjacency matrix of a given size. In a fully bipartite network, there are two distinct groups of actors and each actor is unconnected to any members of their group but to all members of the other group. This means that there will be no trianglular closures, which means that if $i$ is connected to $j$ and $i$ is connected to $k$ we can be absolutely certain that $j$ and $k$ are not connected. The graph with the largest lowest eigenvalue is the complete graph, where every vertex is connected to every other vertex.

\section{Figure 3 about here.}

To illustrate how changes in a network affect the lowest eigenvalue, we construct four stylized networks of five actors each, presented in Figure 3. Figure 3(a) illustrates a network that is is bipartite and has the smallest possible value for $\lambda_{\text {min }}$. In Figure $3(\mathrm{~b})$ we add a link to the bipartite network; this increases $\lambda_{\min }$. The network in $3(\mathrm{c})$ is the bipartite network with one link removed; again this increases $\lambda_{\text {min }}$ compared to the bipartite network. Finally, in $3(\mathrm{~d})$ we have the full network where all actors are connected to all other actors-this network has a lowest eigenvalue of 1 , the largest possible value for $\lambda_{\min }$.

In Figure 4, we see similar dynamics for the lowest eigenvalue when we look at all possible adjacency matrices. In subfigure 4(a), for all possible $5 \times 5$ adjacency matrices, the lowest eigenvalue of a particular matrix is compared to the number of links in that matrix. As we can see, there is a non-linear relationship between the number of links (density) and the value for the lowest eigenvalue. The largest lowest eigenvalues can be found in dense (many links) and sparse (few links) networks. Hence, according to Bramoullé et al. (2011) we should find unique

\footnotetext{
${ }^{4}$ Formally, $\lambda_{\min }$ is the smallest scalar that solves the equation $\mathbf{A} v=\lambda v$, where $\mathbf{A}$ is the $n \times n$ matrix of interest, $v$ is the $n \times 1$ eigenvector, and $\lambda$ is the eigenvalue.
} 
equilibria in both dense and sparse networks, whereas multiple equilibria and corner solutions become more likely in the medium range of possible linkages.

$$
\text { Figure } 4 \text { about here. }
$$

Another way of understanding the link between the lowest eigenvalue and the density of a network is to consider the number of triadic closures. A triadic closure is established if actors $i$, $j$, and $k$ are connected by links $a_{i j}, a_{i k}$, and $a_{j k}$ forming a triangular relationship. This implies that in a network with a high number of triadic closures, behavior of actor $i$ has a more local effect on the behavior of other members in the network. Hence, equilibria in networks with a high of number triadic closures are more likely to be unique. In Figure 4(b) the size of the dots correspond to magnitude of the lowest eigenvalue (small dots correspond to small values). Holding the number of links constant, an increase in triadic closures leads to higher values of the lowest eigenvalue (larger dots). Similarly, if the number of triadic closures is held constant, adding more links leads to smaller lowest eigenvalue (smaller dots).

Empirical Implications. An important aspect of the approach taken by Bramoullé et al. (2011) is that if the uniqueness condition is not met, the Nash equilibrium is a corner solution (small lowest eigenvalue). However, what we are interested in is how networks that foster corner solutions translate into aggregate efforts. An analytic approach to this question is fairly difficult, because we would need comparative statics across different network sizes and different network structures. $^{5}$ Thus, we turn to simulate aggregate effort by using the actual anti-government networks we observe in our data. These simulations give us precise empirical implications given $\overline{5}$ Bramoullé et al. (2011) provide comparative statics for some cases. First, if there are multiple possible equilibria, equilibria with fewer active agents always have a higher level of aggregate action. Second, if a unique equilibria exists, this equilibria has the highest aggregate effort for this particular $\delta$ and A. Any small or large increase in $\delta$ or any additional link in $\mathbf{A}$ always leads to an equilibrium with lower total effort. Finally, if there is a local equilibria, an increase in $\delta$ or any additional link in $\mathbf{A}$ that leads to equilibria with a similar or smaller sets of agents will also lead to a decrease in aggregate effort. 
the theoretical model and the observed anti-government network structures. This also allows us to make empirically testable predictions about the relationship between the smallest lowest eigenvalue and aggregate effort.

Figure 5 about here.

We assume that the actors have a utility function like in equation (1) and best reply functions as in (2). We normalize the optimal level of effort in isolation $\bar{e}_{i}=1$ for all actors. The networks we consider are the observed anti-government network interactions $\mathbf{A}_{\mathbf{t}}$, where $t$ stands for time. We have an anti-government network represented by the corresponding adjacency matrix for each month in the period from March 2001 to December 2010. A detailed description of how we arrive at these networks is given in the next section. We start our simulations at $e_{i}=0$ for all $i$ and let actors decide sequentially on their optimal effort level according to equation (2). This is repeated 100 times, but the effort levels usually converge to their equilibrium value after a few iterations. The sum of the equilibrium efforts by each actor gives the overall effort level. This allows us to look at the relationship between the lowest eigenvalue of our anti-government network and the equilibrium aggregate efforts.

Figure 5 summarizes the results of our simulation. As the lowest eigenvalue decreases on the horizontal axis, aggregate effort increases on the vertical axis. We can also show that given our anti-government network structures over time, we expect increasing levels of aggregate effort. Overall, the simulation results suggest that we expect a greater aggregate effort of the antigovernment network when multiple equilibria and corner solutions become more likely. As is discussed in the previous section, having a low value of $\lambda_{\min }$ represents network where there are few triads. In these networks there are much stronger incentives for corner solutions, where one actor provides all the effort, while triadic closures lend themselves to interior solutions where all actors provide some effort. These simulations confirm our hunch that corner solutions are associated with a higher aggregate amount of effort. Hence, periods of network structures that promote these outcomes (those with very negative values of $\lambda_{\min }$ and few triads) should lead to 
an increase in conflictual behavior on the aggregate level between the government and members of the anti-government network (see Table 1).

Table 1 about here.

\section{EMPIRICAL MODEL}

We analyze the effect of anti-government network interactions (in-group) on conflictual behavior with the government (out-group). More specifically, we predict the total number of conflictual events between the government and members of the anti-government network per month as a function of $\lambda_{\min }(\mathbf{A})_{t-1}$, the lowest eigenvalue of the network $\mathbf{A}$ at time $t-1$. In the following section, we introduce our data and present the operationalization of our key concepts and variables. This includes a detailed description of how we leverage latent network estimation to infer the anti-government network structure. This is followed by an outline of our estimation procedure.

Data. The main data we use in this study were collected as part of the ICEWS project, which is aimed at developing a conflict early warning system for U.S. government decision makers. This project is described in O'Brien (2010) and its initial scope was for 29 countries in the U.S. Pacific Command, including Thailand. Our dependent and main independent variables are based on event data from a large database of news stories over the period of 1997 to 2010. The ICEWS data were collected via a Defense Advanced Research Project Agency (DARPA) funded project that created a dataset of over two million machine-coded daily events occurring between relevant actors within twenty-nine countries in the the Asia-Pacific region. ICEWS utilized news articles from over 75 electronic regional and international news sources and machine coded these events, using the Penn State Event Data Project's TABARI (Text Analysis By Augmented Replacement Instructions) software program (Schrodt, 2009) and a commercially developed, java variant (JABARI). TABARI and JABARI used sparse parsing and pattern recognition techniques to machine-code daily political events based primarily on a categorical coding scheme developed by the Conflict and Mediation Event Observation (CAMEO) project 
(Schrodt and Yilmaz, 2007; Gerner et al., 2009). This ICEWS dataset is the current goldstandard for event data (D'Orazio et al., 2011:p. 4).

Dependent Variable. The empirical implications of our theoretical model are that the antigovernment network structure impacts the conflictual activity between anti-government groups and the government. Hence, our dependent variable measures the total number of conflictual events between members of the anti-government network and the government as indicated by the ICEWS data. Conflictual events include verbal and material conflict as coded in CAMEO (Schrodt and Yilmaz, 2007; Gerner et al., 2009). For our analysis we aggregate the number of conflictual interactions to the monthly level. Figure 2 (above) displays the number of conflictual events from January 1998 through December 2010.

\section{Main Explanatory Variable: Lowest Eigenvalue of the Anti-Government Network.}

Our main hypothesis suggests a negative relationship between the number of total conflictual events between anti-government groups and the government and the lowest eigenvalue of the anti-government network. To arrive at this main independent variable, three steps are involved. First, we define which groups are considered to be members in the anti-government network. We then leverage event data on the interactions among these groups to infer on their connectedness through latent network analysis. Finally, we compute the lowest eigenvalue for the anti-government network in each month. We describe the steps in turn.

Anti-Government Network. A key concept in this study is the anti-government network. We propose an operational definition that accounts for the informality of domestic alliances and focuses on the actual activity against the government. An actor becomes a member of the antigovernment network if it has more conflictual than cooperative interactions with the government and stays a member until it has more cooperative than conflictual interactions in a given month. ${ }^{6}$ A group also drops out of the network if it has not had any conflictual interactions

${ }^{6}$ Specifically, the CAMEO verb codes used to identify cooperative events were 3 (express intent to cooperate), 5 (engage in diplomatic cooperation), 6 (engage in material cooperation), 7 (provide aid), and 8 (yield). The verb codes to identify conflictual events were 10 (demand), 11 (disapprove), 12 (reject), 13 (threaten), 14 (protest), 15 
for 24 months. This cutoff functions as a good compromise that effectively removes actors no longer opposed to the government, yet retains anti-goverment groups that may be free-riding. Our data set includes a total of 24 non-government actors that are potential members of the anti-government network, but on average there are about 15 different, non-governmental actors in any month. The upper line in Figure6 6 represents the size of the anti-government network for each month in the data set. The size of the anti-government network increases over time and becomes stable in size at the end of 2006. In addition, we can distinguish between active and non-active network members in each month. The lower line in Figure6 6 represents the number of network members that have conflictual events with the government in a given month. The maximal number of active anti-government actors in a given month is seven. This suggests that there is indeed free-riding.

The cast of actors in Thai domestic politics is complicated and ever changing. We have detected substantial activity of over two dozen salient actors that had substantial interactions during the study period. The identification of the potential actors was based on whether they showed any activity in our data and whether they pursued political goals in our observation period. These are delineated in Table 2 .

$$
\begin{aligned}
& \hline \text { Table } 2 \text { about here. } \\
& \hline \text { Figure } 6 \text { about here. }
\end{aligned}
$$

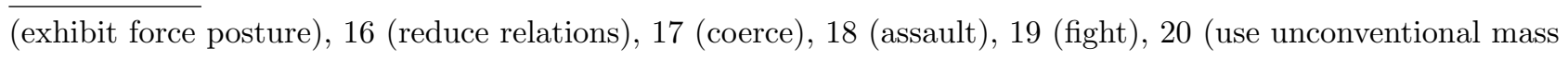
violence). See http://web.ku.edu/ keds/cameo.dir/CAMEO.CDB.09b5.pdf for further information on the CAMEO coding scheme. An example for a cooperative event between members of the anti-government network is a news report from January 1, 2005: "[The 'People's Alliance for Democracy'] also urged the Democrat, Chart Thai and Mahachon parties to patch up their differences and form an opposition alliance against Thai Rak Thai." An example for a conflictive event between a member of the anti-government network and the government can be found in a news report on July 3, 2006: "Authorities reported one murder, one drive-by shooting and a brief but fierce gun battle over the weekend in the southern provinces between troops and rebels." 
Adjacency of Anti-Government Groups. Having defined the members of the anti-government network, we are able to infer the positions of anti-government groups in the network. In a first step, we simple define connectedness $\left(a_{i j}=1\right)$ of anti-government actors if they have cooperative events with each other and unconnectedness $\left(a_{i j}=0\right)$ if actors do not have cooperative events. Coding this for every month in our observation period allows us to construct adjacency matrices that reflect the structure of the anti-government network based on observed interactions. We believe that the adjacency matrices are a good starting point to think about anti-government networks, but we want to stress that these matrices are based on observed values and only capture first-order dependencies. They do not account for the fact that connectivity can arise by being a friend of a friend or by unobserved variables. To capture higher order relationships that might also matter for public good provision, we estimate the latent positions of antigovernment groups and infer the anti-government network structure.

Latent Positions of Anti-Government Groups. Positions of anti-government actors reflect their closeness to one another, preferences for similar policies, and propensity to interact cooperatively. ${ }^{7}$ In order to attain higher order network positions, we rely on a latent space approach to social network analysis (Hoff et al., 2002, Hoff, 2005; Handcock et al., 2007). This class of models, unlike other stochastic models, can trace three common features of social networks at the same time: transitivity, homophily by attributes, and clustering (Handcock et al., 2007). Transitivity exists if two actors that are tied to a third actor are more likely to interact than actors that are not. Homophily refers to the notion that the likelihood of a tie between actors depends on common characteristics or attributes. While exponential random graph models, for example, can capture some forms of transitivity and homophily (Frank and Strauss, 1986, Snijders et al., 2006), they have difficulties with higher levels of dependency. Latent position models address the issue that clustering can be driven by homophily on unobserved variables Gabbay (2008) uses social space to examine the interrelationships among terrorist groups in terms of their ideology and targeting policies in Iraq. 
or endogenous attributes of the network. These can include, for example, positioning around central actors and self-selection mechanisms (Handcock et al., 2007). As mentioned above, the underlying data to infer the actors' latent positions in our study are based on the observed cooperative events between actors.

More formally, the latent space approach assumes that each actor in a network $\mathbf{A}$ has an unobserved position in a social space (Hoff et al. 2002). The position in the latent space is related to the probability of interacting with any of the other actors. In our framework, closeness between two actors in the latent space refers to a higher probability of positive interaction, whereas actors that are positioned further away in the latent space have a higher probability of hostile behavior against each other. The data that is modeled consists of a $n \times n$ matrix $\mathbf{Y}$, with entries $y_{i j}$ representing the observed relation between actor $i$ and $j$. In addition, we can include covariate information $\mathbf{X}=\left\{x_{i j}\right\}$ that is dyad specific. Therefore, a model for the connectivity matrix could take the following form: $y_{i j}=\beta^{T} x_{i j}+\epsilon_{i j}$. Notice however that by standard assumptions, the errors should be independently and identically distributed (i.i.d.). Hence, we need to further decompose the error term to account for the structure that we expect to arise from the network interdependencies. The most general error decomposition can be written as: $\epsilon_{i j}=a_{i}+b_{j}+\gamma_{i j}$, where $a, b$, and $\gamma$ are random variables, which allow for sender, receiver, and dyad specific components.

This decomposition leads to a generalized linear mixed-effects model in which dyads $i j$ are treated as conditionally independent given the random effects.

$$
\begin{aligned}
& \theta_{i j}=\beta^{T} x_{i j}+a_{i}+b_{i}+\gamma_{i j} \\
& E\left(y_{i j} \mid \theta_{i j}\right)=g\left(\theta_{i j}\right) \\
& p\left(y_{12}, \ldots, y_{n, n-1} \mid \theta_{12} \ldots, \theta_{n, n-1}\right)=\prod_{i \neq j} p\left(y_{i j} \mid \theta_{i j}\right)
\end{aligned}
$$

This formulation captures first-order dependence through $\beta^{T} x_{i j}$ and second-order dependence through the structure in the error term. However, network data may also entail third-order 
dependencies that include transitivity, balance, and clusterability. Third-order dependencies can be captured by a bilinear effect that is added to the linear random effects:

$$
\epsilon_{i j}=a_{i}+b_{j}+\gamma_{i j}+u_{k}^{T} v_{k}
$$

where $u_{k}^{T} v_{k}$ is a $k$-dimensional random effect for each member of the dyad in $k$ dimensions. The dot product is then taken because if $i$ and $k$ are similar in their magnitude and scale, then the bilinear effect between $i j$ will be very close to the effect between $j k$, this allows us to capture not only the unit specific factors, and the dyad specific factors, but also third-order factors which describe the properties of triads. For symmetric sociomatrices, the latent space positions are represented by a single latent dimension, $z$, yielding an inner product $z_{k}^{T} z_{k}$ (Hoff, 2005).

To estimate the latent space for our data we proceed as follows. First, we identify all cooperative events among members of the anti-government network for every month $t$. More specifically, we aggregate the last 36 months up to $t$ to gain a sufficient amount of observable network information. We then construct the adjacency matrix $\mathbf{A}_{\text {observed }}$ based on the observed values, where we code $a_{i j}=1$ if a dyad $i j$ has any cooperative events and 0 otherwise. Based on this information, we infer the latent network positions of the anti-government actors in a two-dimensional space and use procrustes rotation to make the networks comparable over time. ${ }^{8}$ Figure 7 shows the resulting latent positions for anti-government actors for June 2001, February 2004, and May 2007. In Thailand, June 2001 was a much calmer time period than February 2004 where insurgent violence motivated police crackdowns in southern regions, and May of 2007 where protests heightened for a few months following the military coup and the official banning of Thaksin's Thai Rak Thai party. As Figure 7 shows, the anti-government network changes in shape and size over time. Actors that are close in space have more cooperative interactions with

\footnotetext{
8 All analyses and graphs were run using $\mathrm{R}$ version 2.15.1. To estimate the latent positions, we use the supplementary R code from Hoff (2005) available at http://www.stat.washington.edu/hoff/Code/hoff_ 2005_jasa/gbme.r. Procrustes rotation was performed using the R package vegan, Version 2.0-6.
} 
each another and have similar cooperative behavior patterns with other actors in the network. The differently colored dots allow for the visual identification of the positions of the groups in the latent space.

Figure 7 about here.

Lowest Eigenvalues. As a starting point, we compute the lowest eigenvalue of the anti-government network using the observed adjacency matrix $\mathbf{A}_{\text {latent }}$, which we denote with $\lambda_{\min }\left(\mathbf{A}_{\text {observed }}\right)$. In a second step we compute the lowest eigenvalue of the networks using the latent positions. To achieve highest possible congruence with our theoretical framework, we transform the positional information into a adjacency matrix $\mathbf{A}_{\text {latent }}$, where $a_{i j}=1$ if the distance between $i$ and $j$ is smaller than the average distance in a particular network. The smallest eigenvalue of $\mathbf{A}_{\text {latent }}$ is denoted by $\lambda_{\min }\left(\mathbf{A}_{\text {latent }}\right)$. Figure 8 displays $\lambda_{\min }\left(\mathbf{A}_{\text {latent }}\right)$ for our observation period. It also shows the latent networks for three selected months to give an impression how the lowest eigenvalue changes with the latent network structure in our data.

Figure 8 about here.

Control Variables. In addition to event data, we include a number of control variables in our statistical model. We include the number of anti-government network members to account for the network size and also the number of attacked and attacking members to control for network activity. In addition, we include a number of structural variables that are commonly used in the literature to predict conflict. GDP growth is lagged by three months and taken from the World Development Indicators (various issues). Violence tends to be higher when elections are close, so we control for this using dates taken from electionguide.org, with additional information where needed from the Archigos data set (Goemans et al., 2009). We also include the Polity score (http://www.systemicpeace.org/polity/polity4.htm), lagged by three months. Finally, our variable for events in similar countries is contextually lagged wherein the weighting matrix represents the total event flows from country $i$ to country $j$ in 
each month. This is used to weight the number of rebellions in countries with similar event profiles.

Estimation Procedure. We estimate a series of event-count models to test our main hypothesis. Since our our dependent variable is over-dispersed under a Poisson distribution assumption, we use negative binomial regression estimators that account for over-dispersion.

\section{RESULTS}

We proceed by estimating four negative binomial regression models. The first model includes $\lambda_{\text {min }}\left(\mathbf{A}_{\text {observed }}\right)$ obtained from the observed adjacency matrix (observed network model). The second model includes $\lambda_{\min }\left(\mathbf{A}_{\text {latent }}\right)$ resulting from the latent space analysis (latent network model), and the third model (smoothed latent network model) includes a smoothed version (three month moving average) of this value. Finally, the fourth model excludes all of our network measures (structural model). The results can be found in Figure 9. Positive coefficients imply that increasing values of an explanatory variable increase the number of conflictual events. ${ }^{9}$ Note that the coefficients of the negative binomial models are the result of an exponential parametrization. This means that the interpretation of the coefficients is not straightforward since the exponential parameterization implies that each coefficient is dependent on all other stochastic and non-stochastic parts of the model. Nonetheless, Figure 9 allows us to provide a first assessment of our main hypotheses. In line with our theoretical argument, small lowest eigenvalues of the anti-government networks are associated with higher levels of conflictual events between the government and the anti-government network. The observed network model and the smoothed latent network model have slightly better fit diagnostics (in terms of AIC

\footnotetext{
${ }^{9}$ To make the effects comparable, we plot the coefficients from regression models after the variables have been scaled. The substantive results are the same as with the centered and scaled variables. A table of the results of all four models in numerical form with the original and standardized variables is given in the Appendix materials found on our Dataverse archive http://dvn.iq.harvard.edu/dvn/dv/mward
} 
and BIC) than the latent network model. We proceed by discussing the network effects for these two models.

Figure 9 about here.

Effect of the Lowest Network Eigenvalue. To provide a more meaningful interpretation of our estimation results, Figure 10 gives a visual interpretation for the observed network and the smoothed latent network model. Our theory predicts that networks where there are dense ties among the anti-government network, meaing that the groups are close in latent space, will feature equilibria where all groups put some effort into the anti-government cause, and lead to less aggregate conflict. We calculate the predicted number of conflictual events between the government and members of the anti-government network (vertical axis) across all values of $\lambda_{\min }(\mathbf{A})_{t-1}$ in the data set (horizontal axis) and provide 95 percent confidence intervals by simulation, holding all continuous control variables at their mean and dichotomous variables at their mode. A rug plot at the bottom of the panel displays the actual distribution of the lowest network eigenvalues in our data. Figure 10 suggests that the lowest eigenvalue of the anti-government network at $t-1$ decreases the aggregate level of conflictual events. While we are cautious to interpret these results as causal evidence, it does support our hypothesis that small lowest eigenvalues are associated with an increasing number of conflictual events.

Comparing the effects for the raw and the smoothed latent network model, Figure 10 reveals that the smoothed latent network model predicts more conflictual events at smaller values of the lowest eigenvalue and less conflictual events at larger values of the lowest eigenvalue. However, the uncertainty around the predicted number of conflictual events is slightly larger in the smoothed latent network model.

Taking a more detailed perspective, these findings provide insight into the conflict dynamics in Thailand. During periods in which the anti-government network is characterized by small lowest eigenvalues, important changes within this network occurred. For example, between the end of 2006 and the beginning of 2007 the anti-government network experienced a shift as many anti-Thaksin supporters and groups solidified with one another to form the strong opposition 
party known as the People's Alliance for Democracy (PAD). As a response, Thaksin called an election to try and demonstrate that he still had the support of the Thai people. The election degenerated into a one-candidate race and resolved little. From this time until the military coup, anti-Thaksin opposition grew and division within the anti-government network increased (Ockey, 2007).

\section{Figure 10 about here.}

Model Fit. Having provided an interpretation of the effect of network structure, we turn our attention to the overall model fit and how it is improved by the inclusion of our network variables. Figure 11 provides quartile-prediction plots for the structural (left panel) and the smoothed latent network model (right panel). These plots capture the extent to which a model correctly predicts the number of conflictual events in a given month. In each panel the actual number of conflictual events between the government and anti-government network members is divided into quartiles and compared to the quartiles of its predicted values. A perfect model would be able to assign the predicted values to the same quartiles as the corresponding true values. The diagonal from the bottom left to the upper right would then be filled with the correctly predicted levels of conflictual events and the off-diagonal cells would be empty. Comparing the structural model in 11(a) to the network model in 11(b) reveals that the inclusion of anti-government network measures improves the prediction of conflictual events. The network model predicts the quartile of 48 months correctly, while the structural model only gets 43 right. This is the case even though the network model slightly overestimates low conflict events months. However, since our goal is to improve the prediction of high levels of conflictual events, at least from our perspective, the overestimation of low intensity months is less worrisome than a possible underestimation of high level events.

$$
\text { Figure } 11 \text { about here. }
$$




\section{Out-of-Sample Predictions}

In addition to our in-sample predictions, we also evaluate how the network model performs out-of-sample. We estimate a negative binomial model with the smoothed latent network model specification but exclude the last 12 months from the initial estimation. Using the estimated coefficients from the test sample we predict the total number of conflictual events between the anti-government network and the government between January 2010 and April 2010 (Period 1). We then include these four months in our test sample, run an additional negative binomial model, and use the resulting estimates to predict conflictual events with the government between May 2010 and August 2010 (Period 2). We repeat this procedure for our final out-of-sample prediction between September 2010 and December 2010 (Period 3). Hence, we have three fourmonth prediction periods to compare how well the network model and the structural model do out-of-sample. Figure 12 displays the results. The grey line refers to the actual number of conflictual events. The black solid line represents our network model out-of-sample predictions with their confidence band. The network model does very well in the first prediction period, while it over-predicts in the second and third period. The network model fares better than the structural model (dashed line) in 2 out of 3 prediction periods. It predicts the downward trend of conflict in 2011, while the structural model predicts an upward trend.

Figure 12 about here.

We also provide the Root Mean Squared Error (RMSE) and Continuous Rank Probability Score (CRPS) for every out-of-sample month. ${ }^{10}$ The left panel in Figure 13 plots the RMSE for the structural (dotted line) and smoothed latent network model, while the right panel does

\footnotetext{
${ }^{10} \mathrm{RMSE}=\sqrt{\frac{\left(\sum \hat{y}-y\right)^{2}}{n}}$ is an assessment of the point prediction $\hat{y}$ compared to the observed value $y$. However, it does not consider the probability density function of our forecasts (Brandt et al. 2011). Hence, we consider the $\mathrm{CRPS}=\int_{-\infty}^{\infty}\left(C_{\hat{y}}(x)-C_{y}(x)\right)^{2} d x$, which is the difference between the total areas of the predicted and observed cumulative functions.
} 
the same for the CRPS. Both statistics indicate that the network model fares better in 8 out of 12 months.

$$
\text { Figure } 13 \text { about here. }
$$

\section{Conclusion}

In this project, we have woven together three threads of conflict research. In the first thread we have used state-of-the-art data collection to gather information about the ebb and flow of political activity in a contentious society, Thailand. This data collection was undertaken in the context of the ICEWS project funded by DARPA. We used these data to gather information about the relevant contentious groups in Thailand, aggregated them on a monthly basis, and combined them with other covariates for our conflict model. The second thread was to take a network perspective on the interactions among anti-government groups and to use innovative network analysis techniques to derive the implicit latent network among the main anti-government actors in Thailand. In doing so we derived the underlying probabilities that each specific group of actors would cooperate with other groups. These latent propensities, statistically estimated with modern Bayesian techniques, provided the topography of the network. Our third thread was to take recent results from game theory that suggest that the structure of a network determines the type of equilibrium that arises in a public goods game. We look at the lowest eigenvalue as a way of determining the conflictual behavior of the underlying latent networks with the government.

In evaluating the fabric created by weaving these three threads together, we build a model aimed at predicting the level of conflictual events in Thailand. We use data on the number of such events that occur in each month from 2001-2010 as our primary dependent variable. The statistical results suggest that in addition to important structural variables such as the proximity to elections or the expansion of the economy, the network structure as measured by the lowest eigenvalue substantially increases the statistical power of the model. In order to further examine our results, we used our developed model to predict conflictual events in 
months that were reserved as test data, and had not been used the parameter estimation. Our model does not provide perfect predictions about anti-government conflict in Thailand, but it does predict it quite accurately. Indeed, it turns out that model components mapped from the network configurations do a better job in out-of-sample tests than the structural aspects of our model alone. This has persuaded us that the network structure can be usefully employed to understand the outbreak and evolution of episodic violence, even in societies as complicated and fractious as Thailand.

This study not only suggests some generalizable patterns of anti-government network structures and domestic conflict, it also highlights some important insights about the continuous conflict in Thailand. While many commentators focus on the dyadic relationship between individual anti-government groups and the government, less emphasis has been put on the relationships between anti-government groups and how this affects conflictual behavior. Our results suggest that the anti-government network dynamics lead to conflict despite favorable economic and structural circumstances. This helps to provide an answer to our initial puzzle that asks why we see recurring conflict in Thailand even though structural models would predict peace and stability. Though these insights were applied to the Thailand case, we see no reason to think they are specific to Thailand.

A striking finding of this study is that network structure, as captured by the lowest eigenvalue of the anti-government network, is associated with higher numbers of conflictual events. As opposition groups move further away from each other, thus having a lower probability of cooperation, we observe more conflictual events with the government. To some extent this may seem counterintuitive, since many studies suggest that more coherent anti-government movements are more effective in fighting the government (Weinstein, 2007). In fact, some literature suggests that the level of violence is high when the opposition is united, yet our theory and evidence suggest that violence is high when the opposition is polarized and fractionalized. We believe that the results of our study demonstrate support for the more general notion that network structures among anti-government groups are an important aspect of conflict dynamics. 
This study is a first attempt to identify more general relationships between anti-government networks and conflictual behavior with the government, and it provides analytical tools for further applications in a variety of situations. Assessing our theoretical and empirical framework in other contexts will be necessary to gain further understanding about the fundamental strategic dynamics within anti-government networks. 


\section{REFERENCES}

Bramoullé, Yann, and Rachel Kranton. "Public Goods in Networks." Journal of Economic Theory 135: (2007) 478-494.

Bramoullé, Yann, Rachel Kranton, and Martin D’Amours. "Strategic Interactions and Networks." http://bit.ly/yjI3HR, 2011. Duke University, Department of Economics, Working Paper.

Brandt, Patrick T., John R. Freeman, and Philip A. Schrodt. "Real Time, Time Series Forecasting of Political Conflict." Conflict Management and Peace Science 28, 1: (2011) 41-64.

Collier, Paul, and Anke Hoeffler. "Greed and grievance in civil war." Oxford Economic Papers 56: (2004) 563-595.

Cunningham, David, Kristian Skrede Gleditsch, and Idean Salehyan. "It Takes Two: A Dyadic Analysis of Civil War Duration and Outcome." Journal of Conflict Resolution 53, 4: (2009) $570-597$.

Cunningham, David E. "Veto Players and Civil War Duration." American Journal of Political Science 50, 4: (2006) 875-892.

D'Orazio, Vito, James E. Yonamine, and Philip A. Schrodt. "Predicting Intra-State Conflict Onset: An Event Data Approach using Euclidean and Levenshtein Distance Measures." Presented at the 69th Annual Meeting of the Midwest Political Science Association, Chicago, Il, USA., 2011.

Eck, Kristine, and Lisa Hultman. "One-sided Violance against Civilians in War: Insights from New Fatality Data." Journal of Peace Research 44, 2: (2007) 233-246.

Fearon, James D., and David D. Laitin. "Ethnicity, insurgency, and civil war." American Political Science Review 97, 1: (2003) 75-90.

Fjelde, Hanne, and Desirée Nilsson. "Rebel Against Rebel: Explaining Inter-group Violence." Presented at the North American Meeting Peace Science Society (International) .

Frank, Ove, and David Strauss. "Markov Graphs." Journal of the American Statistical Association 81, 395: (1986) 832-842. 
Gabbay, Michael. "Mapping the Factional Struture of the Sunni Insurgency in Iraq." Counter Terrorism Center Sentinel 1, 4: (2008) 10-12.

Galeotti, Andrea, Sanjeev Goyal, Matthew O. Jackson, Fernando Vega-Renondo, and Leeat Yariv. "Network Games." Review of Economic Studies 77, 2: (2010) 218-244.

Gerner, Deborah J., Philip A. Schrodt, and Omur Yilmaz. "Conflict and Mediation Event Observations (CAMEO): An Event Data Framework for a Post-Cold War World." In International Conflict Mediation: New Approaches and Findings, edited by Jacob Bercovitcch, and Scott Sigmund Gartner, New York: Routledge, 2009, Studies in Security and Conflict Management, chapter 13, 287-304.

Gleditsch, Kristian Skrede. "Expanded Trade and GDP Data." Journal of Conflict Resolution 46, 5: (2002) 712-724.

Gleditsch, Nils Petter, Peter Wallensteen, Mikael Eriksson, Margareta Sollenberg, and Havard Strand. "Armed Conflict 1946-2001: A New Dataset." Journal of Peace Research 39, 5: (2002) 615-637.

Goemans, Hein E., Kristian Skrede Gleditsch, and Giacomo Chiozza. "Introducing Archigos: A Data Set of Political Leaders." Journal of Peace Research 46, 2: (2009) 269-283.

Handcock, Mark S., Adrian E. Raftery, and Jeremy M. Tantrum. "Model-based Clustering for Social Networks." Journal of the Royal Statistical Society: Series A (Statistics in Society) 170, 2: (2007) 301-354.

Hegre, Håvard, Tanja Ellingsen, Scott Gates, and Nils Petter Gleditsch. "Toward a Democratic Civil Peace? Democracy, Political Change, and Civil War, 1816-1992." American Political Science Review 95, 1: (2001) 33-48.

Hegre, Håvard, and Nicholas Sambanis. "Sensitivity Analysis of Empirical Results on Civil War Onset." Journal of Conflict Resolution 50, 4: (2006) 508-535.

Hicken, Allen. "Party Fabrication: Constitutional Reform and the Rise of Thai Rak Thai." Journal of East Asian Studies 6, 3: (2006) 381-408. 
Hoff, Peter D. "Bilinear Mixed-Effects Models for Dyadic Data." Journal of the American Statistical Association 100, 4690: (2005) 286-295.

Hoff, Peter D., Adrian E. Raftery, and Mark S. Handcock. "Latent Space Approaches to Social Network Analysis." Journal of the American Statistical Association 97, 460: (2002) 1090-1098.

Lichbach, Mark Irving. The Rebel's Dilemma. Ann Arbor: University of Michigan Press, 1995.

Monderer, Dov, and Lloyd S. Shapley. "Potential Games." Games and Economic Behavior 14, 1: (1996) 124-143.

O'Brien, Sean P. "Crisis Early Warning and Decision Support: Contemporary Approaches and Thoughts on Future Research." International Studies Review 12, 1: (2010) 87-104.

Ockey, James. "Thailand in 2006: Retreat to military rule." Asian Survey 47, 1: (2007) 133-140.

Olson, Mancur, and Richard Zeckhauser. "An Economic Theory of Alliances." The Review of Economics and Statistics 48, 3: (1966) 266-279.

Sandler, Todd, and Keith Hartley. "Economics of Alliances: The Lessons for Collective Action." Journal of Economic Literature 39, 3: (2001) 869-896.

Schrodt, Philip A. "TABARI: Textual Analysis by Augmented Replacement Instructions, Version 0.7." http://eventdata.psu.edu/tabari.dir/tabari.manual.0.7.3b3.pdf, 2009.

Schrodt, Philip A., and Omur Yilmaz. "CAMEO Conflict and Mediation Event Observations Codebook." http://eventdata.psu.edu/cameo.dir/CAMEO.CDB.09b5.pdf, 2007.

Siegel, David A. "Social Networks and Collective Action." American Journal of Political Science 53, 1: (2009) 122-138.

—. "When Does Repression Work?: Collective Action in Social Networks." Journal of Politics 73, 1: (2011) 232-247.

Snijders, Tom A. B., Philippa E. Pattison, Garry L. Robins, and Mark S. Handcock. "New Specifications for Exponential Random Graph Models." Sociological Methodology 36, 1: (2006) $99-153$. 
Staniland, Paul. "Organizing Insurgency: Networks, Resources, and Rebellion in South Asia." International Security 37, 1: (2012) 142-177.

Tullock, Gordon. "The Paradox of Revolution." Public Choice 11, 1: (1971) 89-99.

UCDP. "UCDP Battle-Related Deaths Dataset v.5-2010." http://www.ucdp.uu.se, 2011. Uppsala Conflict Data Program, Uppsala University.

Weinstein, Jeremy M. Inside Rebellion: The Politics of Insurgent Violence. Cambridge: Cambridge University Press, 2007. 


\section{FIGURES}

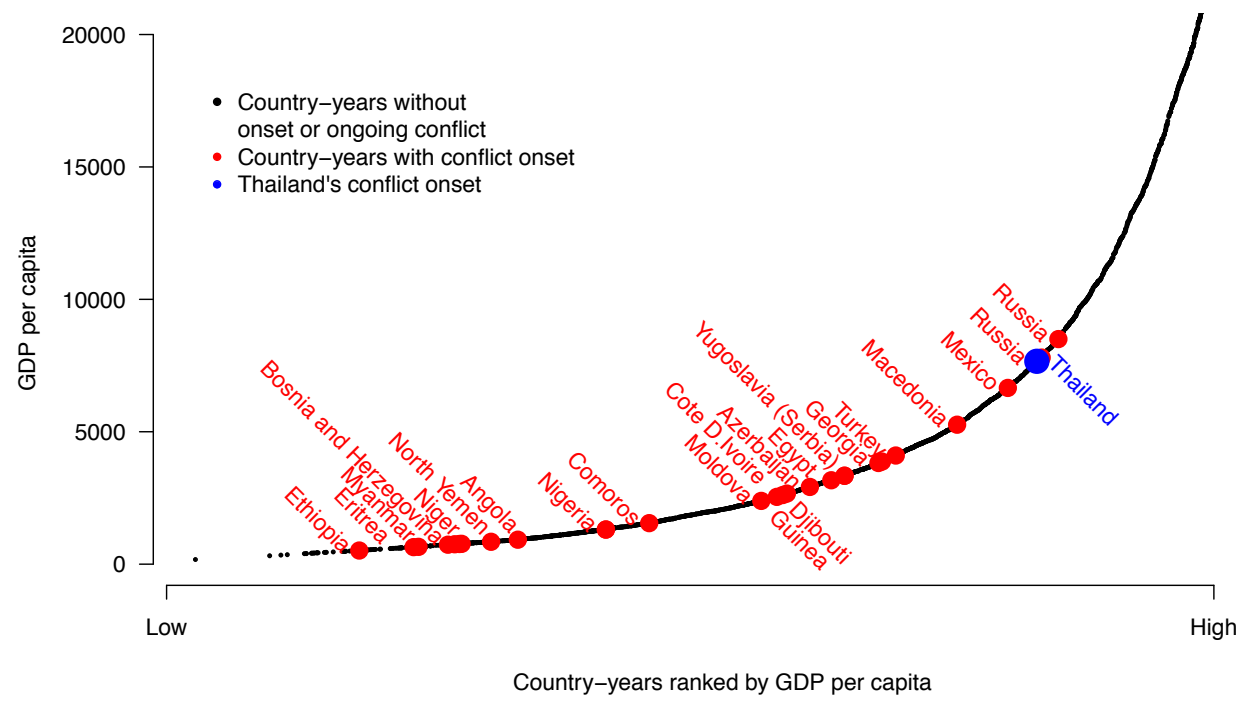

Figure 1. Uppsala Conflict Data Project civil conflicts after 1990 in relation to GDP per capita. Country-years with GDP per capita less than \$20,000. Labels correspond to country-years with a civil conflict onset. 


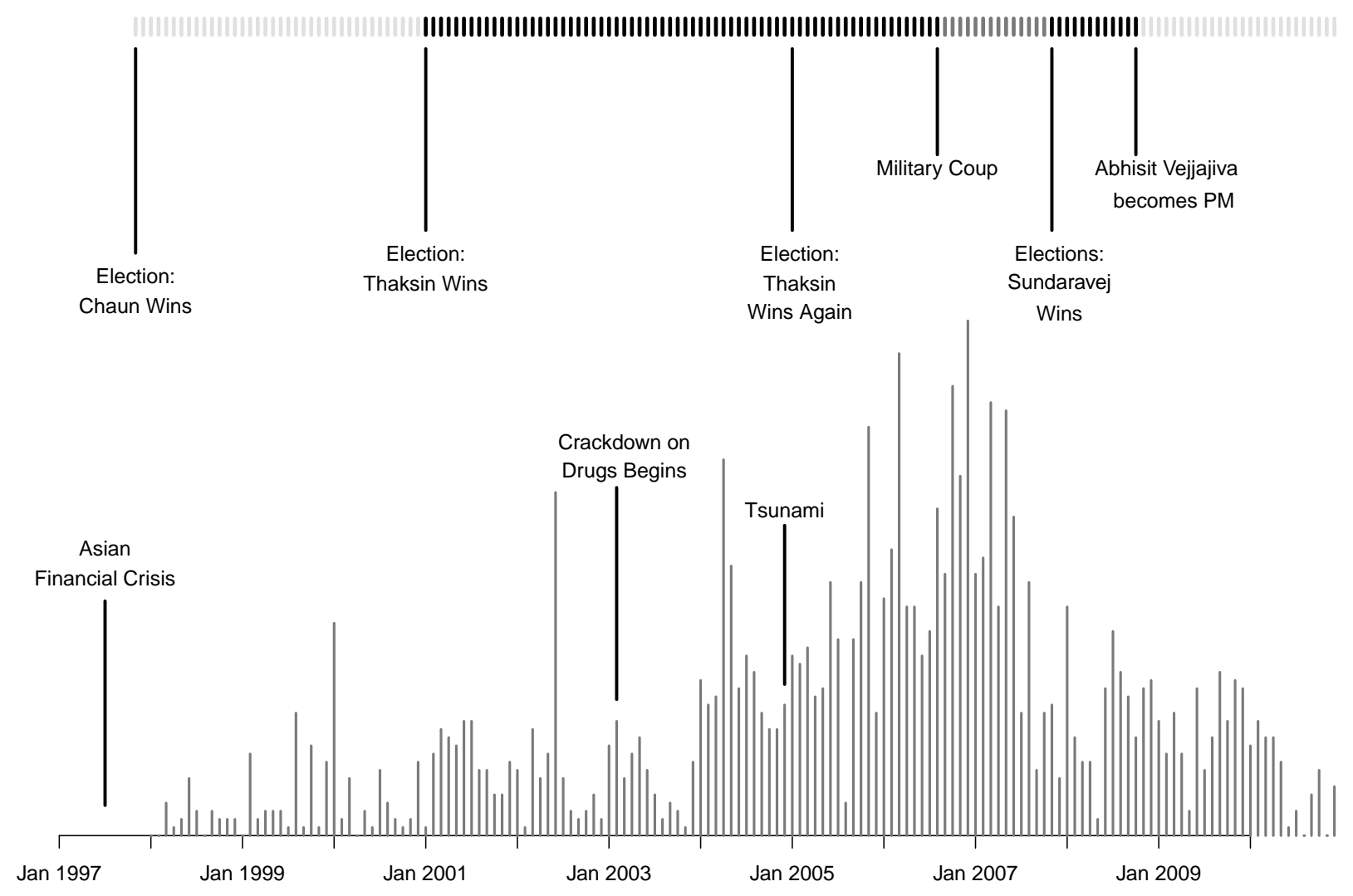

FIGURE 2. The upper rug represents the different parties that are in power during the observation period: the lightest gray intervals refers to the Democratic Party, the black intervals represent the Thai Rak Thai party (as well as the People's Power Party, which is considered to be the banned Thai Rak Thai party reincarnate) and the medium shade of gray denotes the period of military rule following the coup. The bottom rug illustrates the pattern of conflictual events during this period, beginning in 1998. The labels surrounding the bottom rug serve as markers for other significant events occurring during this time. 


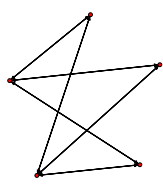

(a) $\lambda_{\min }=-2.45$

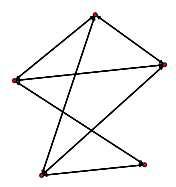

(b) $\lambda_{\min }=-2.17$

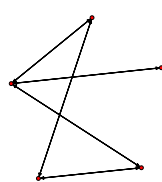

(c) $\lambda_{\min }=-2.14$

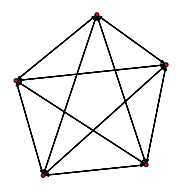

(d) $\lambda_{\min }=-1$

FiguRE 3 . The lowest eigenvalue $\lambda_{\min }$ for four stylized networks 


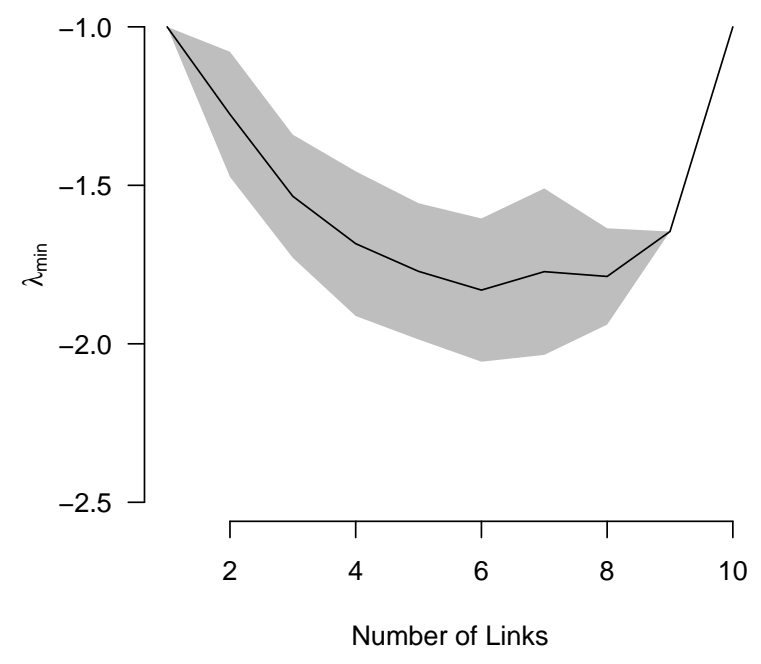

(a) $\lambda_{\min }$ and number of links

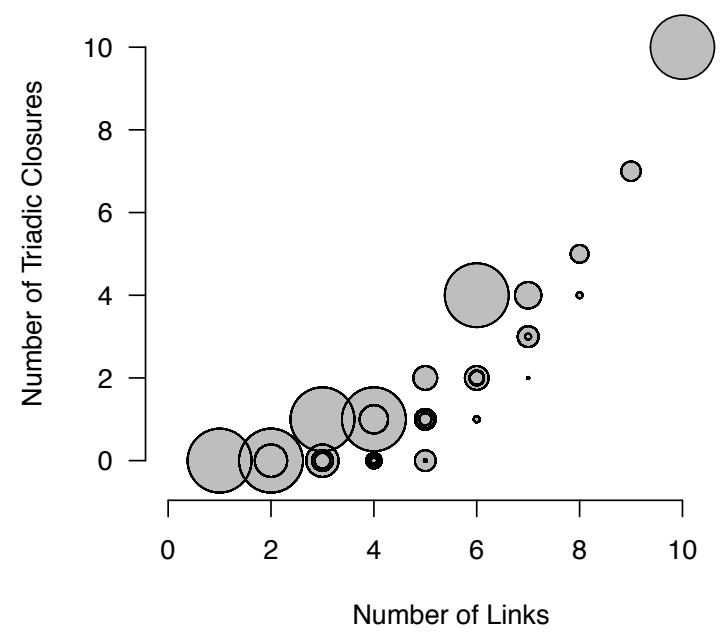

(b) $\lambda_{\text {min }}$ conditional on triadic closures and links

FIGURE 4. Left panel shows the non-linear relationship between $\lambda_{\min }$ and number of links for all possible $5 \times 5$ adjacency matrices. The panel displays the mean $\lambda_{\text {min }}$ with its standard error. Right panel displays values of $\lambda_{\min }$ conditional on the number of triadic closures and the number of links in a network. The size of the circle indicates the size of the lowest eigenvalue for each combination (small circles indicate small values, large circles indicate values close to -1). 


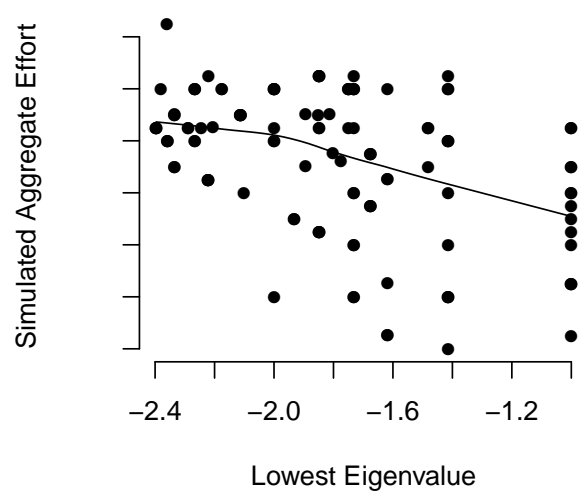

(a)

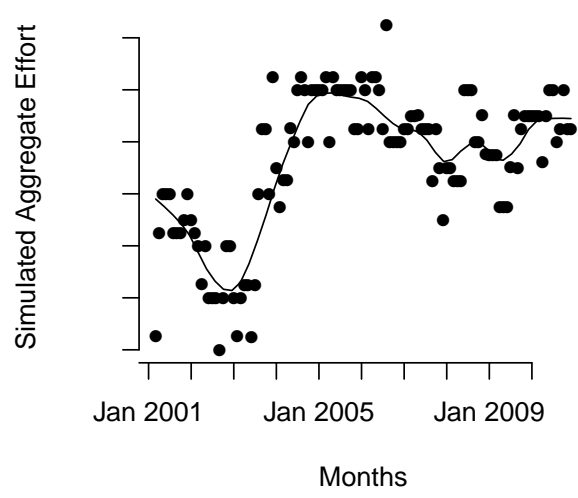

(b)

Figure 5. Lowest eigenvalue and simulated aggregate effort. Figure 5(a) displays the relationship between the lowest eigenvalue of a network and the simulated aggregate effort. Figure 5(b) shows the simulated aggregate effort for each month. 


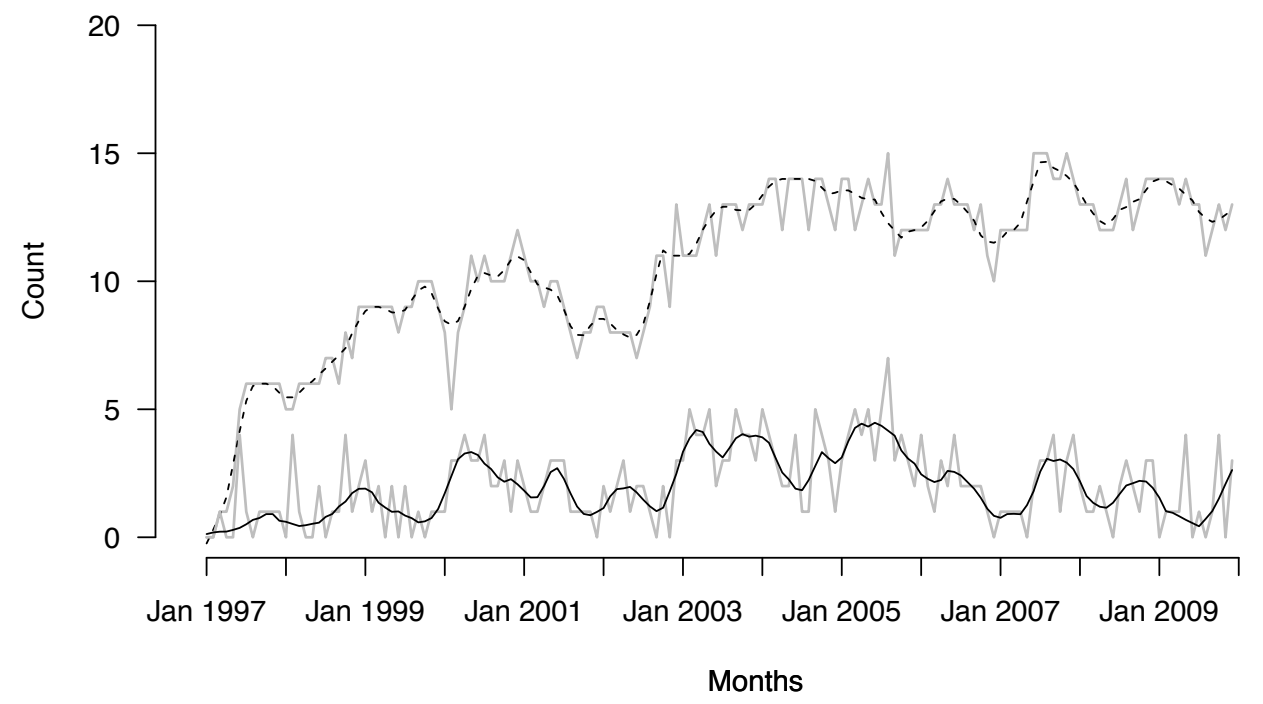

FIGURE 6. Anti-government network size over time (overlay: dashed line using a lowess function with smoother span $f=0.05$ ) and the number of active network members (overlay: solid line using a lowess function with smoother span $f=$ $0.05)$. 


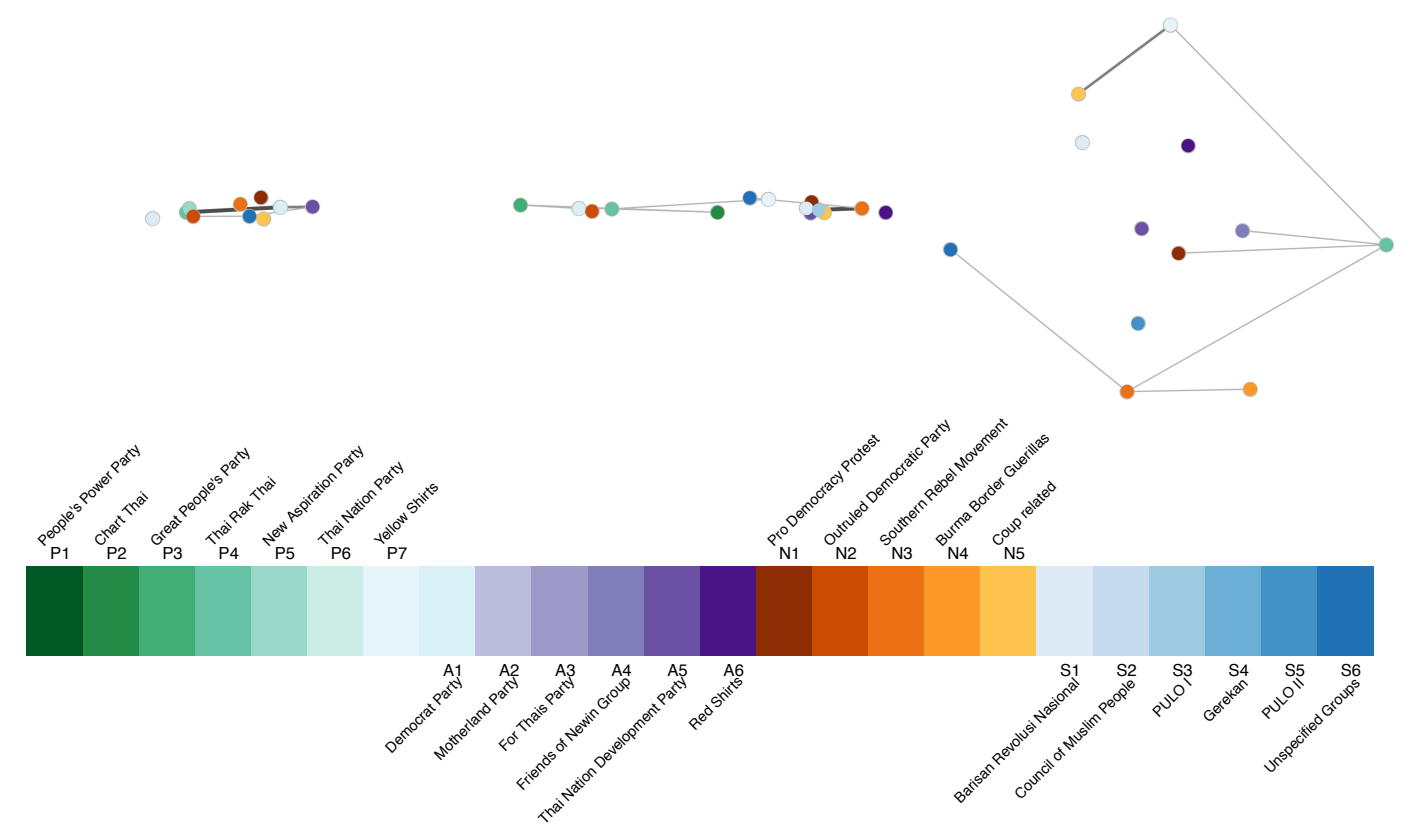

FiguRE 7. Latent positions of anti-government network members. From left: June $2001\left(\lambda_{\min }\left(\mathbf{A}_{\text {latent }}\right)=\right.$-2.29); February $2004\left(\lambda_{\min }\left(\mathbf{A}_{\text {latent }}\right)=\right.$-2.38); May $2007\left(\lambda_{\text {min }}\left(\mathbf{A}_{\text {latent }}\right)=-2.57\right)$. The lines represent the cooperative linkages between the network members, with darker and thicker lines indicating more cooperation. 


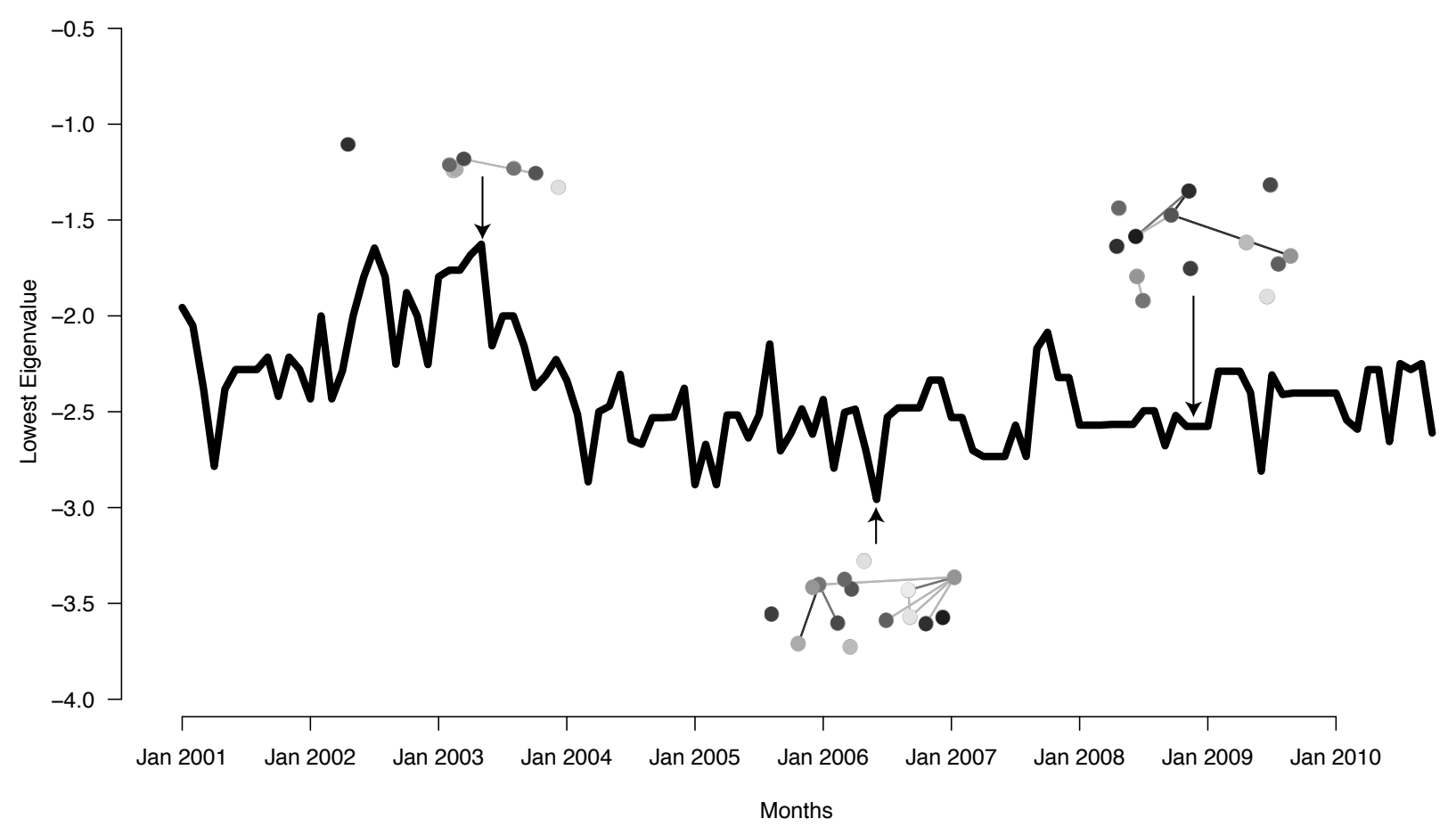

FIGURE 8. $\lambda_{\text {min }}\left(\mathbf{A}_{\text {latent }}\right)$ for our observation period and latent networks for three selected months. 
FiguRE 9. Estimation results for negative binomial regression models. Dependent variable: Total number of conflictual events in month $t$. The dots give the point estimate for each variable and the lines indicate the $95 \%$ confidence interval. The top, black line, refers to the observed network model. The second line represents the latent network model. The third line gives the results for the smoothed latent network model and the last line represents the structural model. For purposes of comparison the estimates are based on standardized explanatory variables.

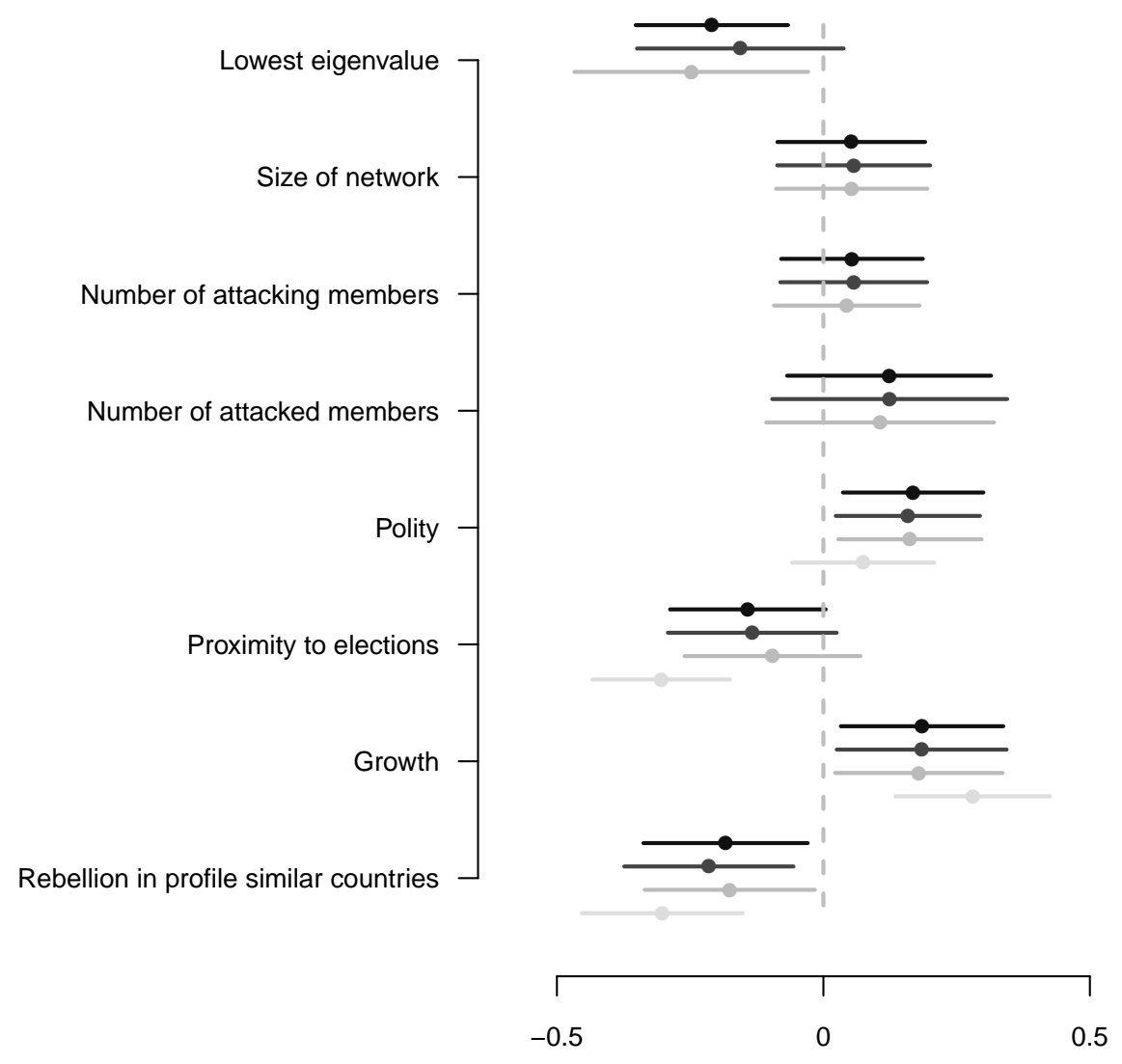




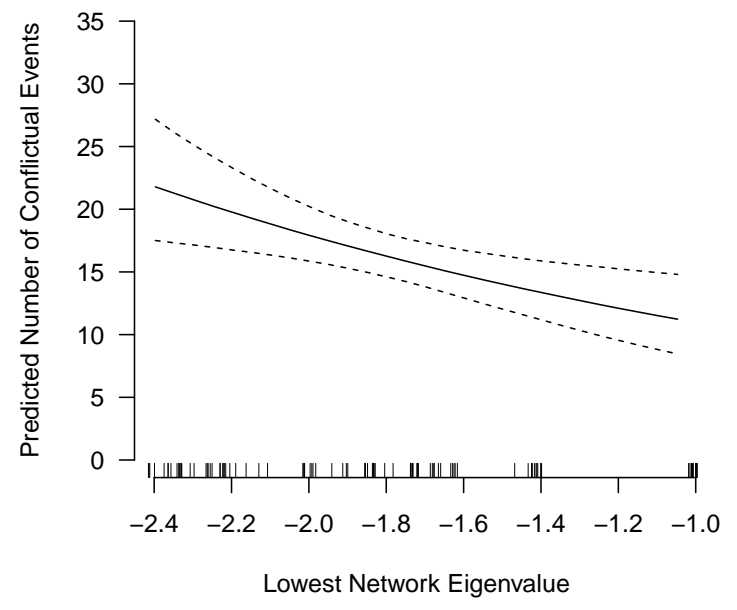

(a) Raw network positions

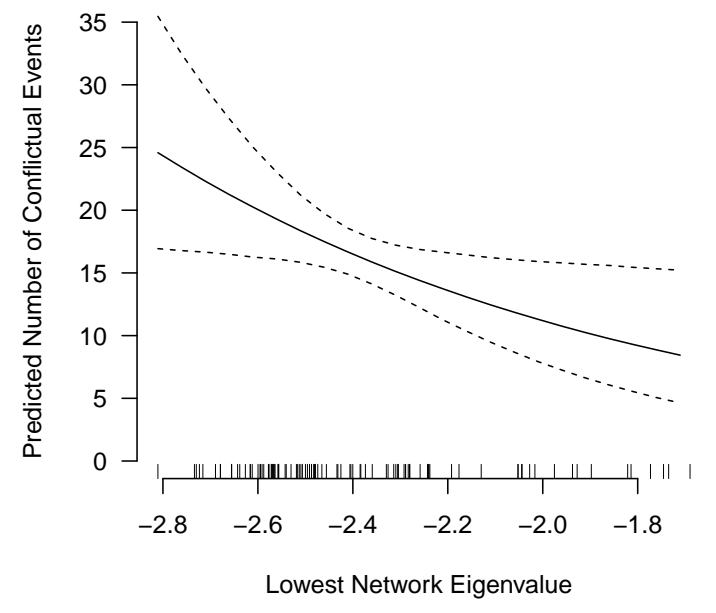

(b) Latent network positions

FiguRE 10. Predicted number of conflictual events between the government and anti-government members given the lowest eigenvalue of the anti-government network at time $t-1$. Dashed lines represent simulated 95 percent confidence intervals. Figure 10(a) refers to the raw network model; Figure 10(b) corresponds to the smoothed latent network model. 


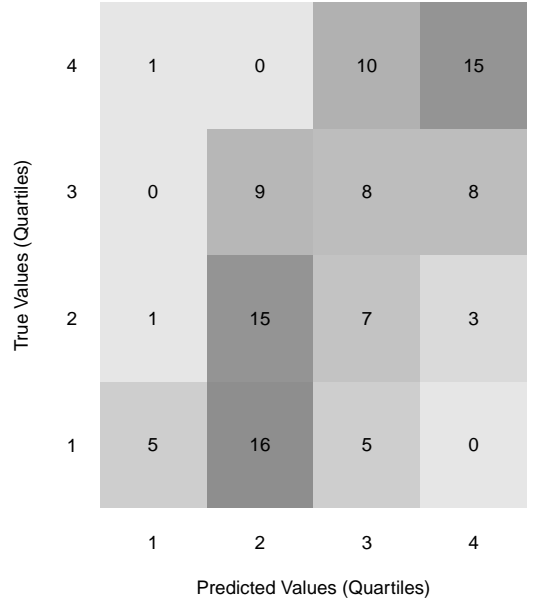

(a) Structural

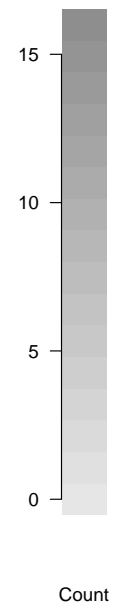

Count

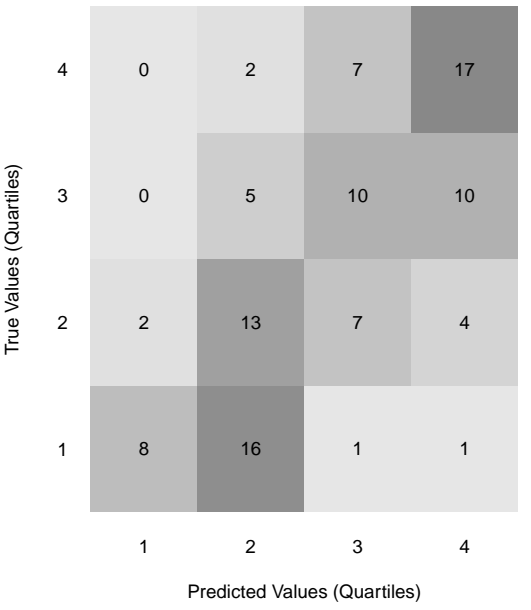

(b) Network

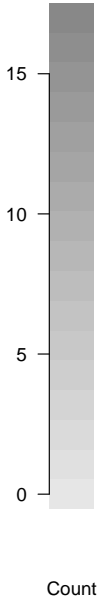

ount

FIGURE 11. Quartile-prediction plots. Figure 11(a) refers to the structural model which excludes the network related explanatory variables and Figure 11(b) is for the network model. 


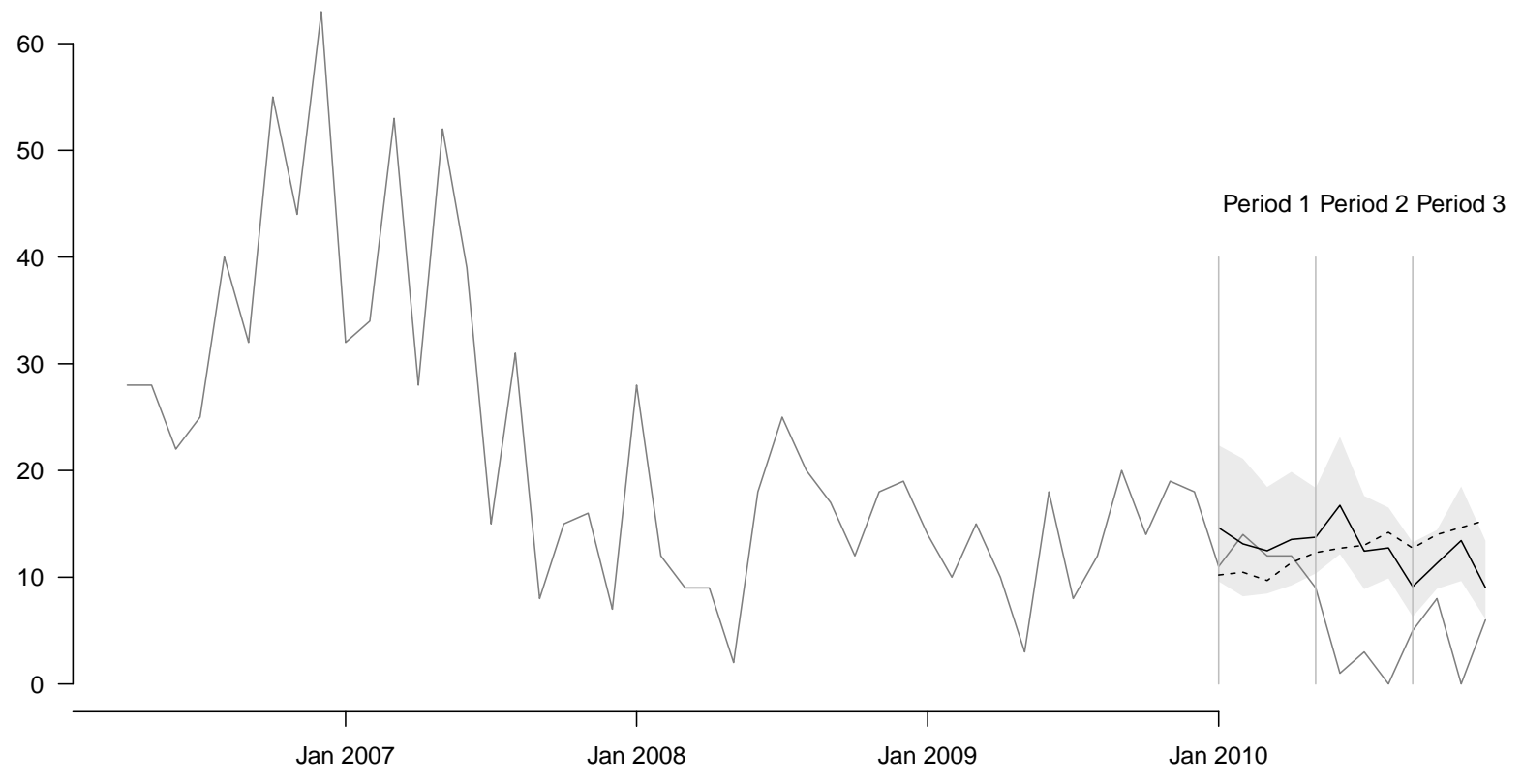

FiguRE 12. Out-of-sample prediction periods. The grey line shows the actual conflictual events between the government and members of the anti-government network. The black line represents the network model out-of-sample predictions for January 2010-April 2010 (Period 1), May 2010-August 2010 (Period 2), and September 2010-December 2010 (Period 3). The dashed line corresponds to the out-of-sample predictions of the structural model. 
FiguRE 13. RMSE and CRPS for out-of-sample predictions. Values for the smoothed latent model are represented by the black lines. The dotted line refers to the performance of the structural model. Black dots identify better out-sample predictions by the the smoothed latent network model. Black triangles indicate better performance by the structural model.
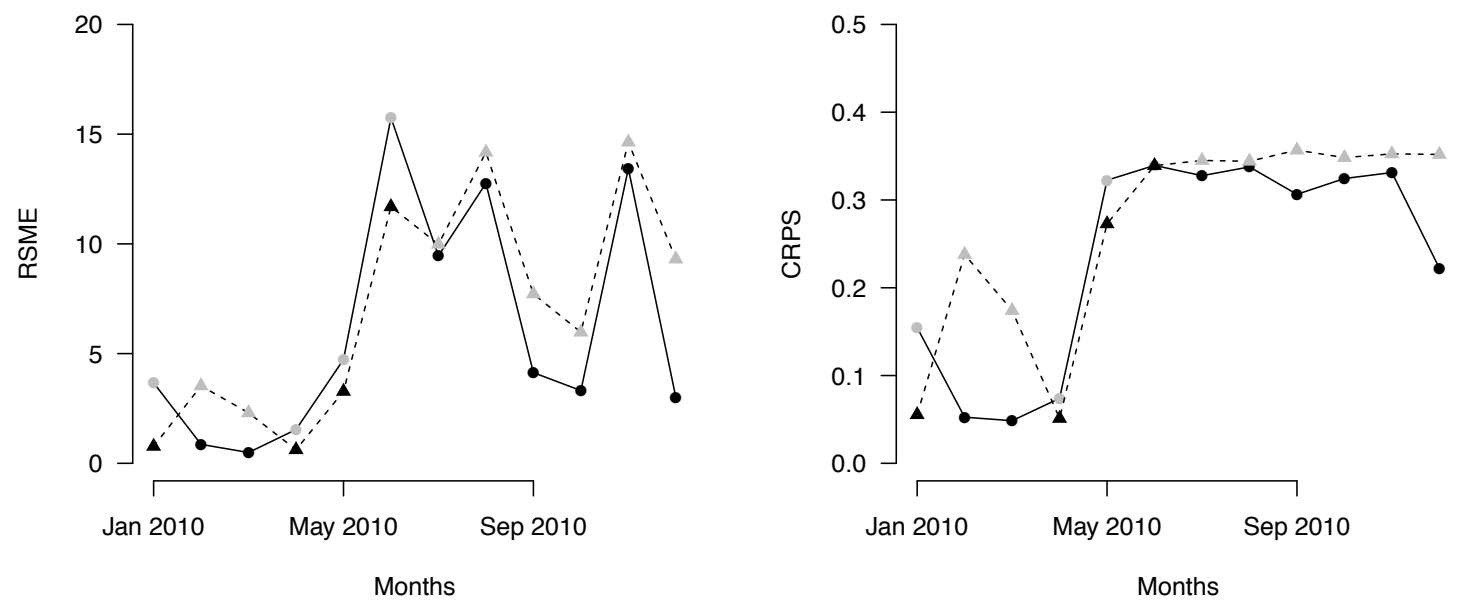


\section{TABLES}

TABLE 1. Main empirical implications of the network argument. Note that the lowest eigenvalue $\lambda_{\min }(\mathbf{A})$ is always negative.

Interior or corner solutions

Large $\lambda_{\min }(\mathbf{A}) \longrightarrow$ Unique interior or corner equilibrium $\longrightarrow$ Less aggregate effort

Corner solutions

Small $\lambda_{\min }(\mathbf{A}) \quad \longrightarrow \quad$ Multiple corner solutions $\quad \longrightarrow \quad$ More aggregate effort 
TABLE 2. Significant groups among the anti-government network in Thailand.

\begin{tabular}{llll}
\hline People's Power Party & Democrat Party & Pro Democracy Protest & Barisan Revolusi National \\
Chart Thai & Motherland Party & Outruled Democratic Party & Council of Muslim People \\
Great Peoples' Party & For Thais Party & Southern Rebel Movement & PULO I \\
Thai Rak Thai & Friends of Newin Group & Burma Border Guardians & Gerekan \\
New Aspiration Party & Thai Nation Development & Coup related groups & PULO II \\
$\begin{array}{l}\text { Thai Nation Party } \\
\text { Yellow Shirts }\end{array}$ & Red Shirts & & Unspecified Groups \\
\hline
\end{tabular}


Nils W. Metternich: Department of Political Science

Current address: University College London, Tavistock Square, London, UK

E-mail address: nm86@duke.edu

Cassy Dorff: Department of Political Science

Current address: Duke University, Durham, NC, 27708, USA

E-mail address: cassy.dorff@duke.edu

Max Gallop: Department of Political Science

Current address: Duke University, Durham, NC, 27708, USA

E-mail address: max.gallop@duke.edu

Simon Weschle: Department of Political Science

Current address: Duke University, Durham, NC, 27708, USA

E-mail address: simon.weschle@duke.edu

Michael D. Ward: Department of Political Science

Current address: Duke University, Durham, NC, 27708, USA

E-mail address: michael.d.ward@duke.edu 